\title{
Telomerase- and angiogenesis-related gene responses to irradiation in human umbilical vein endothelial cells
}

\author{
HYUN CHANG ${ }^{1-3}$, SUN YOUNG RHA ${ }^{1,2,4}$, HEI-CHEUL JEUNG ${ }^{1,2,4}$, KYU HYUN PARK ${ }^{2}$, \\ TAE SOO KIM ${ }^{2,4}$, YONG-BAE KIM ${ }^{2,5}$ and HYUN CHEOL CHUNG ${ }^{1,2,4,6}$
}

\begin{abstract}
${ }^{1}$ Division of Medical Oncology, Department of Internal Medicine, ${ }^{2}$ Cancer Metastasis Research Center, Yonsei Cancer Center, Yonsei University College of Medicine, Seodaemun-gu, Seoul 120-752; ${ }^{3}$ Division of Hematology and Medical Oncology, Department of Internal Medicine, Seoul National University Bundang Hospital, Seongnam-si, Gyeonggi-do 463-707;

${ }^{4}$ National Biochip Research Center, ${ }^{5}$ Department of Radiation Oncology, ${ }^{6}$ Severance Biomedical Science Institute, Yonsei University College of Medicine, Seodaemun-gu, Seoul 120-752, Republic of Korea
\end{abstract}

Received January 23, 2013; Accepted March 5, 2013

DOI: $10.3892 / \mathrm{ijmm} .2013 .1300$

\begin{abstract}
In this study, we investigated the effects of ionizing radiation (IR) on human umbilical vein endothelial cells (HUVECs) in the context of senescence. HUVECs at passage number (PN)1, PN2 and PN3 were exposed to irradiation (2 Gy). The growth rate of the HUVECS was measured by proliferation assay and senescence-associated $\beta$-galactosidase assay was used to measure the number of senescent cells. Telomerase activity and the expression of telomerase- and angiogenesis-related genes were measured by telomerase assay and real-time PCR, respectively. The number of senescent cells was significantly increased in the irradiated HUVECs at all PNs. Compared to the controls, telomerase activity, the expression of human telomerase reverse transcriptase ( $h T E R T$ ) and $c-M y c$ in the irradiated HUVECs were downregulated during serial passage. The downregulation of vascular endothelial growth factor $(V E G F)$ was observed in the irradiated HUVECs as the PN increased. The data presented in this study may aid in the understanding of the mechanisms behind IR-induced EC senescence and telomerase- and angiogenesis-related gene response.
\end{abstract}

Correspondence to: Dr Hyun Cheol Chung, Division of Medical Oncology, Department of Internal Medicine, Cancer Metastasis Research Center, Yonsei Cancer Center, Yonsei University College of Medicine, 50 Yonsei-ro, Seodaemun-gu, Seoul 120-752, Republic of Korea

E-mail: unchung8@yuhs.ac

\begin{abstract}
Abbreviations: FGF, fibroblast growth factor; CTGF, connective tissue growth factor; EC, endothelial cell; hTERT, human telomerase reverse transcriptase; HUVECs, human umbilical vein endothelial cells; IGFBP4, insulin-like growth factor-binding protein4; IR, ionizing radiation; MCAM, melanoma cell adhesion molecule; PBS, phosphate-buffered saline; PN, passage number; VEGF, vascular endothelial growth factor; vWF, von Willebrand factor
\end{abstract}

Key words: telomerase, endothelial cells, radiation, angiogenesis, genes

\section{Introduction}

The important role of microvasculature in tumor growth has been well established (1). Tumors are known to be angiogenesis-dependent, and thus, the occurrence of endothelial cell (EC) apoptosis in the tumor microvasculature is a critical homeostatic factor regulating the rate of tumor growth. As a result, the effectiveness of tumor therapy may be determined by the responsiveness of the tumor microvascular endothelium, as well as tumor cells themselves to treatment. The activated vascular endothelium is an attractive therapeutic target as it is easily accessible for drugs, is genetically stable (less likely to develop resistance), homogeneous, and cells are in a proliferative state primarily within tumor tissue (2). Garcia-Barros et al reported that microvascular damages regulated tumor cell response to radiation (1).

Telomeres consist of short tandemly repeated DNA sequences. In humans, this sequence is TTAGGG, and the average telomere length is $5-15 \mathrm{~kb}(3)$. When the telomere length is short, it signals the arrest of cell proliferation, senescence and apoptosis (4). Telomere sequences are mainly synthesized by a cellular reverse transcriptase, telomerase, which is an RNA-dependent DNA polymerase that adds telomeric DNA onto telomeres (3). In humans, telomerase has a minimum of two essential components: a functional RNA component ( $h$ TER) that serves as a template for telomeric DNA synthesis and a catalytic protein component with reverse transcriptase activity (hTERT) that adds the telomeric repeats onto the end of the chromosome (5).

Telomerase is highly expressed in the advanced stages of the majority of cancers. Previous studies have shown that targeting telomerase with antisense oligonucleotides against $h$ TERT, as well as pharmacological and genetic approaches, may be a promising cancer therapeutic strategy (6). Vascular ECs have been observed to express hTERT mRNA by in situ hybridization in human astrocytoma (7). There was a significant correlation observed between the level of $h T E R T$ mRNA expression and the proliferation rate of the ECs within the tumor vasculature. In addition, there was a significant correlation observed between the $h T E R T$ mRNA expression level 
and the histological grade of the tumor. Falchetti et al reported that the inhibition of telomerase in human umbilical vein ECs (HUVECs) completely suppressed the angiogenic behavior of these cells in tumor xenografts (8). The hTERT inhibitor, BIBR1532, has been shown to induce vascular smooth muscle cell senescence (9). These findings suggest a contribution of telomerase activity to angiogenesis in ECs in vitro and in vivo.

Tumor angiogenesis involves a number of angiogenic factors, including vascular endothelial growth factor (VEGF), angiopoietin, basic fibroblast growth factor (FGF), and platelet-derived growth factor. VEGF exerts a variety of effects on vascular ECs that together promote the formation of new blood vessels, stimulate ECs to migrate and divide, and profoundly alter their pattern of gene expression $(10,11)$. VEGF has been reported to delay the onset of senescence in microvascular ECs and to reverse the senescence process (12). VEGF has also been shown to exert a radio-protective effect and to promote post-radiation survival in the tumor endothelium (2). Li et al showed that VEGF receptor (VEGFR)2 blockade using monoclonal antibody in ECs attenuated the proliferation, reduced migration and disrupted the differentiation of cells (2). Tie- 1 and Tie- 2 are tyrosine kinases with immunoglobulin-like and EGF-like domains (13). FGF upregulates the telomerase activity of HUVECs (14). Tie-2 is required for EC maintenance and proliferation. The angiopoietins and the Tie-2 receptor are considered key regulators of tumor-induced angiogenesis, cancer growth and metastasis (15).

It has been suggested that the tumor endothelium is quantitatively different from the endothelium derived from normal tissue. However, the normal and tumor endothelium have many similarities, sharing many EC-specific markers. St Croix et al reported 15 pan-endothelial markers that are expressed at substantially higher levels in both normal and tumor-associated endothelium compared with other tissues (16). Pan-endothelial markers are involved in the regulation of tumor angiogenesis $(17,18)$. Among them, collagen type IV, $\alpha 2$ (COL4 $\alpha 2)$ inhibits EC migration and proliferation and induces EC apoptosis (19). Collagen type XVIII, $\alpha 1$ (COL18 $\alpha 1$ ), a highly selective inhibitor of angiogenesis, increases EC apoptosis and decreases the tumor cell expression of several pro-angiogenic and invasive molecules (20). Collagen type VI, $\alpha 1$ (COL6 $\alpha 1)$ is known to govern cell anchorage to the extracellular matrix and is downregulated in multiple myeloma ECs (21). Insulin-like growth factor-binding protein (IGFBP)4, IGFBP7, connective tissue growth factor (CTGF), interferon-induced transmembrane protein 1 (9-27), von Willebrand factor (vWF), and melanoma cell adhesion molecule (MCAM) have also been identified as pan-endothelial markers (16).

Ionizing radiation (IR) exerts powerful antitumor effects as it induces cytotoxicity via DNA damage. IR targets both tumors and ECs. The radiosensitivity of the tumor microvasculature and microvascular damage significantly contributes to tumor response to radiation (11). Thus, targeting an intrinsic treatment threshold in tumor vasculature ECs sensitizes the tumor cells to IR. Considering that IR directly induces DNA double-strand breaks, it is possible that cellular senescence is activated under these conditions (22). EC senescence may be an important factor for determining angiogenic activity following IR. Igarashi et al reported that the majority of growing ECs (80-90\%) exhibited the senescence phenotype 3-5 days following exposure to 8 Gy of IR (23). It has been reported that the DNA damage response elicited by IR-induced DNA double-strand breaks is associated with telomere-initiated cellular senescence (24).

However, the mechanisms of action of IR in tumor angiogenesis are largely unknown (23). We hypothesized that the effect of IR-induced EC senescence may be associated with changes in telomerase- and angiogenesis-related gene expression. To examine this hypothesis, we investigated the effects of IR on telomerase- and angiogenesis-related gene expression in HUVECs in vitro.

\section{Materials and methods}

Cell lines. HUVECs were obtained from ATCC (Manassas, VA, USA). HUVECs were grown in Ham's F12K medium (Gibco, Invitrogen, Grand Island, NY, USA) with $2 \mathrm{mM}$ L-glutamine adjusted to contain $1.5 \mathrm{~g} / 1$ sodium bicarbonate and supplemented with $10 \%$ heat-inactivated fetal bovine serum (Omega Scientific, Inc., Tarzana, CA, USA), 100 U/ml penicillin, $100 \mu \mathrm{g} / \mathrm{ml}$ streptomycin and $50 \mu \mathrm{g} / \mathrm{ml}$ endothelial growth supplement (BD Biosciences, Bedford, MA, USA). Cells were incubated in a humidified atmosphere of $5 \% \mathrm{CO}_{2}$ and $95 \%$ air in a $37^{\circ} \mathrm{C}$ incubator.

At confluence (70-80\%), cells were harvested by treatment with $0.05 \%$ Trypsin- $0.02 \%$ ethylenediaminetetraacetic acid (EDTA). Trypsin was inactivated by the addition of $1.25 \mathrm{mg}$ of soybean trypsin inhibitor, and the cells were routinely subcultured at a constant 1:5 split ratio. The passage number (PN) was defined as the number of times cells have been subcultured into a new vessel. HUVECs were used between the first and third PNs.

HUVECs at PN1, PN2 and PN3 were irradiated at room temperature at $2 \mathrm{~Gy} / \mathrm{min}$ with a PRIMART linear accelerator (Siemens AG, Erlangen, Germany). Irradiated HUVECs were cultured for 8 days and were then harvested for the evaluation of gene expression (Fig. 1).

Measurement of growth rate. The growth rate of the HUVECs was examined by proliferation assay. Cells were seeded at $20 \%$ confluence $\left(5 \times 10^{3}\right.$ cells) in a 24 -well plate, and cell numbers were counted using methylene blue staining every $24 \mathrm{~h}$ for 8 days. The growth curve was drawn using the mean cell number of duplicated determinations, and the growth rate was calculated as follows: growth rate $=\ln (\mathrm{N} 2 / \mathrm{N} 1) /(\mathrm{t} 2-\mathrm{t} 1)$; where $\mathrm{N} 1$ and $\mathrm{N} 2$ were the cell numbers at time $1(\mathrm{t} 1)$ and time $2(\mathrm{t} 2)$, respectively.

Senescence-associated $\beta$-galactosidase assay. Senescenceassociated (SA) $\beta$-galactosidase-positive cells were detected using the method described below. Briefly, cell monolayers were washed twice with phosphate-buffered saline (PBS) and fixed with $2 \%$ formaldehyde $/ 0.2 \%$ glutaraldehyde for $5 \mathrm{~min}$. The cells were then washed twice with PBS, and staining solution [ $1 \mathrm{mg} / \mathrm{ml}$ 5-bromo-4-chloro-3-indolyl $\beta$-D-galacto-pyranoside (X-Gal) in dimethylformamide (20 mg/ml, stock), $40 \mathrm{mM}$ citric acid/sodium phosphate buffer ( $\mathrm{pH}$ 6.0), $5 \mathrm{mM}$ potassium ferrocyanide, $5 \mathrm{mM}$ potassium ferricyanide, $150 \mathrm{mM} \mathrm{NaCl}$, $2 \mathrm{mM} \mathrm{MgCl}_{2}$ ] was added. The cells were then incubated at $37^{\circ} \mathrm{C}$ for $16 \mathrm{~h}$ and washed with PBS, and the number of stained cells was counted. 


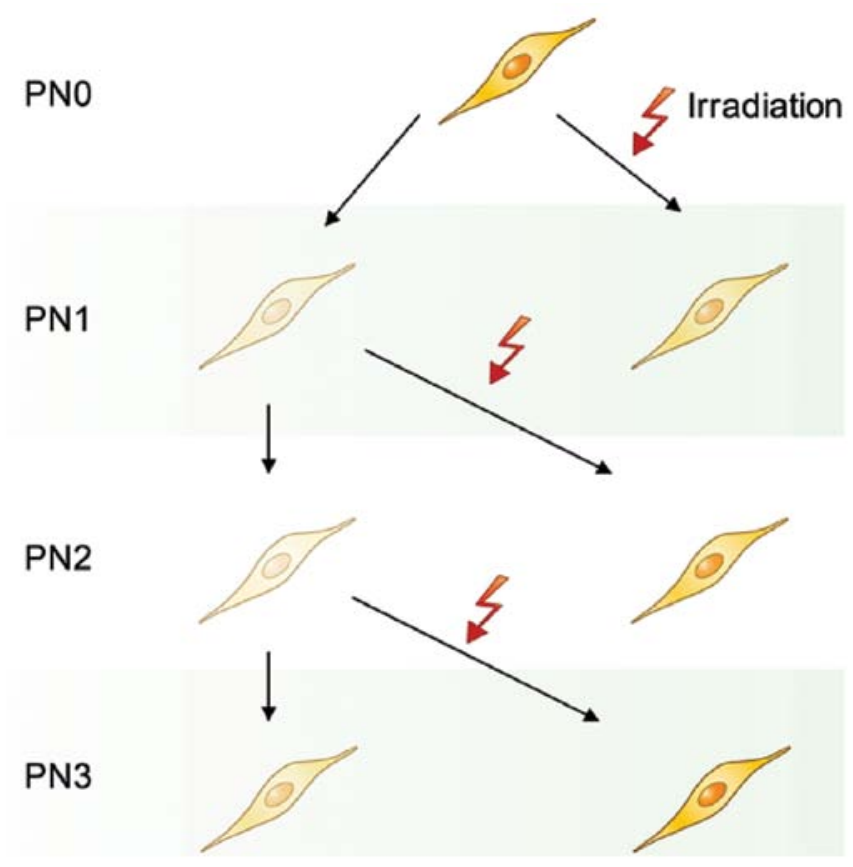

Figure 1. Human umbilical vein endothelial cells (HUVECs) were irradiated at $2 \mathrm{~Gy} / \mathrm{min}$. Irradiated HUVECs were cultured for 8 days and then harvested for the evaluation of gene expression. Cells were routinely subcultured at a constant 1:5 split ratio. PN, passage number.

Telomerase assay. Briefly, the telomeric repeat amplification protocol (TRAP) was performed according to the method described by Kim et al (25), with some modifications. Cells were washed in ice-cold wash buffer $[10 \mathrm{mM}$ HEPES-KOH (pH 7.5), $1.5 \mathrm{mM} \mathrm{MgCl}_{2}, 10 \mathrm{mM} \mathrm{KCl}, 1 \mathrm{mM}$ dithiothreitol], and then with $100 \mu \mathrm{l}$ of ice-cold lysis buffer [10 mM Tris- $\mathrm{HCl}$ (pH 7.5), $1 \mathrm{mM} \mathrm{MgCl}_{2}, 1 \mathrm{mM}$ EGTA, $5 \mathrm{mM}$ 2-mercaptoethanol, 0.1 mM PMSF, 0.5\% CHAPS and $10 \%$ glycerol] in Kontes tubes. The homogenate was placed on ice for $30 \mathrm{~min}$ and centrifuged at $14,000 \mathrm{x}$ g for $30 \mathrm{~min}$ at $4^{\circ} \mathrm{C}$. Supernatants were transferred into frozen vials and stored at $-80^{\circ} \mathrm{C}$. Protein concentration was measured using the Bio-Rad protein assay kit (Bio-Rad Laboratories, Munich, Germany). Telomerase activity was assayed by the TRAP method. A total of $6 \mu \mathrm{g}$ of sample was mixed in $50 \mu \mathrm{l}$ of reaction mixture [forward telomerase substrate (TS) primer (5'-AATCCGTCGAGCAGAGTT-3') (0.1 $\mu \mathrm{g}), 20 \mathrm{mM}$ Tris-HCl (pH 8.3), $1.5 \mathrm{mM} \mathrm{MgCl}$, $63 \mathrm{mM} \mathrm{KCl,} 1 \mathrm{mM}$ EGTA, $0.005 \%$ Tween-20, $0.1 \mathrm{mg}$ bovine serum albumin and $50 \mu \mathrm{M} \mathrm{dNTP}$ including ${ }^{32} \mathrm{P}$-labeled dCTP], and incubated at $20^{\circ} \mathrm{C}$ for $30 \mathrm{~min}$ for the telomerase-mediated extension of TS primers. After heating the mixture at $94^{\circ} \mathrm{C}$ for $3 \mathrm{~min}$ to inactivate telomerase, $1 \mu \mathrm{g}$ of CX primer [5'-(CCCTTA)3CCCTAA-3'] and $2 \mathrm{U}$ of Taq DNA polymerase were added, and the mixture was then subjected to 30 cycles at $94^{\circ} \mathrm{C}$ for $30 \mathrm{sec}, 50^{\circ} \mathrm{C}$ for $30 \mathrm{sec}$ and $72^{\circ} \mathrm{C}$ for $90 \mathrm{sec}$. Polymerase chain reaction (PCR) products were analyzed by electrophoresis on $12 \%$ polyacrylamide non-denaturing gels. The gels were dried and exposed overnight on X-ray films. The criterion for a positive TRAP assay was a hexanucelotide ladder of 3 or more bands. A total of 293 human embryonic kidney cell extracts were used as the positive control. The standard $6 \mu \mathrm{g}$ of protein extract was serially diluted 10- and 100-fold to remove possible false-negative results from the Taq polymerase inhibitor and to create a relative comparison system.

Real-time PCR. Total RNA was collected from the cells using TRIzol reagent. RNA integrity was initially checked on a $1 \%$ agarose gel by confirming the presence of the $18 \mathrm{~S}$ and $28 \mathrm{~S}$ ribosomal RNA bands. Approximately $5 \mu \mathrm{g}$ of total RNA was used to create cDNA using a First Strand cDNA Synthesis kit (MBI Fermentas, Vilnius, Lithuania) according to the manufacturer's instructions. For quantitative real-time PCR, primers and the QuantiTect SYBR-Green PCR kit (Qiagen, Santa Clarita, CA, USA) were used with the Rotor-Gene 2072D real-time PCR machine (Corbett Research, Sydney, Australia). Briefly, in a total reaction mixture volume of $20 \mu \mathrm{l}$ composed of 1X QuantiTect SYBR-Green PCR Master Mix containing HotStarTaq DNA polymerase, QuantiTect SYBR-Green PCR buffer, dNTP mix including dUTP, SYBR Green, ROX (passive reference dye), $5 \mathrm{mM} \mathrm{MgCl}_{2}, 0.5 \mu \mathrm{M}$ primers and $0.5 \mu \mathrm{g}$ of cDNA, PCR was performed as follows: $15 \mathrm{~min}$ at $95^{\circ} \mathrm{C}$ and then 45 cycles of $15 \mathrm{sec}$ at $94^{\circ} \mathrm{C}, 15 \mathrm{sec}$ at $60^{\circ} \mathrm{C}$, and $20 \mathrm{sec}$ at $72^{\circ} \mathrm{C}$. The primers used are listed in Table I. The relative expression level of each gene was calculated by dividing the gene expression of the irradiated HUVECs by that of the control HUVECs at the same PN.

Statistical analysis. An unpaired two-tailed Student's t-test was used for the evaluation of the senescence rate; a P-value $<0.05$ was considered to indicate a statistically significant difference. All analyses were performed using SPSS software for Windows (version 12.0, SPSS, Chicago, IL, USA).

\section{Results}

Changes in biological phenotypes following IR. Following IR, the growth rate was delayed. The mean growth rate of the control cells was $0.156 /$ day at PN1, 0.132/day at PN2 and $0.098 /$ day at PN3. The mean growth rate of the irradiated cells was 0.086/day at PN1, 0.042/day at PN2 and 0.042/day at PN3. The growth inhibition rates following IR treatment were 44.8, 62.2 and $57.1 \%$ at PN1, PN2 and PN3, respectively.

Appearance of senescence following IR. The number of IR-induced senescent cells was significantly increased in the irradiated HUVECs at all PNs (mean \pm SD; PN1, 7.12 \pm 1.1 vs. $32.4 \pm 4.4 \%, \mathrm{P}<0.001 ; \mathrm{PN} 2,11.7 \pm 4.3$ vs. $30.9 \pm 6.2 \%, \mathrm{P}<0.05 ; \mathrm{PN} 3$, $18.6 \pm 3.1$ vs. $43.1 \pm 5.5 \%, \mathrm{P}<0.01)(\mathrm{n}=3$ for each passage) (Fig. 2$)$.

Telomerase activity following IR. In the control cells, there was no difference observed in telomerase activity as the PN increased. However, following IR treatment, there was a $20 \%$ decrease in telomerase activity in the irradiated cells compared to the control cells at PN1, a $20 \%$ reduction at PN2 and a $25 \%$ reduction at $\mathrm{PN} 3$.

Changes in telomerase-related gene expression following $I R$. Compared to the control cells at the corresponding PNs, the downregulation of $h T E R T$ and $h T E R$ was observed in the irradiated HUVECs (Figs. 3 and 6A). The hTERT expression level continuously decreased at all PNs. The expression of Madl decreased at PN1 and 2, but increased by approximately 
Table I. Primers used for real-time PCR.

\begin{tabular}{|c|c|c|}
\hline Gene & Sense sequence $\left(5^{\prime}-3^{\prime}\right)$ & Antisense sequence $\left(5^{\prime}-3^{\prime}\right)$ \\
\hline hTER & CTAACCCTAACTGAGAAGGGCGTAG & GAAGGCGGCAGGCCGAGGCTTTTCC \\
\hline hTERT & CGGAAGAGTGCTCTGGAGCAA & GGATGAAGCGGACTCTGGA \\
\hline hTEP & TCAAGCCAAACCTGAATCTGAG & CCCGAGTGAATCTTTCTACGC \\
\hline c-Myc & AAGTCCTGCGCCTCGCAA & GCCTGTGGCCTCCAGCAGA \\
\hline Mad1 & TTCAGACTTGGACTGTGTCA & GAAGGAAGTCCAGAAGGTTT \\
\hline VEGF & GTGGACATCTTCCAGGAGTA & TCTGCATTCACATTTGTTGT \\
\hline VEGFR-1 & GGCTCTGTGGAAAGTTCAGC & AATCACTTGGAAGAGGGGCT \\
\hline VEGFR-2 & CCCACCCCCAGAAATAAAAT & ACATTTGCCGCTTGGATAAC \\
\hline VEGFR-3 & GCTGAAGCAGAGAGAGAGAA & GTCACACTCCTTGTCCACTT \\
\hline Tie-1 & GTCCTTTGGAGTCCTTCTTT & AAGTTCTCAAACAGCGACAT \\
\hline Tie-2 & CAAAGATGATCACAGGGACT & GAAGGAAGTCCAGAAGGTTT \\
\hline COL $18 \alpha 1$ & CTCCCTGCTCTACACAGAAC & CTCTGGAACTCCTCACAGTC \\
\hline $\operatorname{COL} 4 \alpha 2$ & GACATCGGGGACACTATAAA & ACСТTCTGTTCССТTCTCTC \\
\hline COL6 $\alpha 1$ & ATGCCATGGACTTTATCAAC & GAGTTGCCATCTGAGAAGAG \\
\hline CTGF & CСТCAАTTTCTGAACACCAT & AACAATCTGTTTTGACGGAC \\
\hline IGFBP4 & CACGAGGACCTCTACATCAT & GTCCACACACCAGCACTT \\
\hline IGFBP7 & GGGTCACTATGGAGTTCAAA & TGTAATTTTTGCTGATGCTG \\
\hline $9-27$ & TTACTGGTATTCGGCTCTGT & CACTGTAGACAGGTGTGTGG \\
\hline MCAM & CTGTAAATACCTGGCTCCTG & CACAGGAGACTTTGAAGAGG \\
\hline vWF & GAACGGGTATGAGTGTGAGT & CAAGGTGACTTTCTTTCCTG \\
\hline$\beta$-actin & GGGAATTCAAAACTGGAACGGTGAAGG & GGAAGCTTATCAAAGTCCTCGGCCACA \\
\hline
\end{tabular}

hTERT, human telomerase reverse transcriptase; VEGF, vascular endothelial growth factor; VEGFR, vascular endothelial growth factor receptor; COL4 $\alpha 2$, collagen type IV, $\alpha$ 2; COL18 $\alpha 1$, collagen type XVIII, $\alpha$ 1; COL6 $\alpha 1$, collagen type VI, $\alpha$ 1; IGFBP, insulin-like growth factor-binding protein; CTGF, connective tissue growth factor; MCAM, melanoma cell adhesion molecule; vWF, von Willebrand factor.

3 -fold in the irradiated cells compared to the control cells at PN3 (Figs. 3 and 6A). $c-M y c$ was continuously downregulated at all PNs.

Changes in angiogenesis-related gene expression following $I R$. Compared to the control cells at the corresponding PNs, the downregulation of VEGFR1, VEGFR2, VEGFR3, Tie-1 and Tie-2 was observed in the irradiated HUVECs (Figs. 4 and 6B). $V E G F$ expression decreased as the PN increased compared to the control cells. Among the pan-endothelial markers, $C O L 4 \alpha 2, C O L 18 \alpha 1$ and $C O L 6 \alpha 1$ were downregulated in the irradiated HUVECs at all PNs (Figs. 5 and 6C). The levels of IGFBP4, IGFBP7, CTGF, MCAM, 9-27 and $v W F$ were also downregulated in the irradiated HUVECs (Figs. 5 and 6C).

\section{Discussion}

This study demonstrates that IR is a potent inducer of EC senescence, as well as the downregulation of telomeraserelated genes. Telomere and hTERT are associated with cellular senescence. It has been reported that telomeres in senescent cells directly play a role in DNA damage response, and that uncapped telomeres are associated with DNA damage response proteins (24). Takano et al reported that hTERT

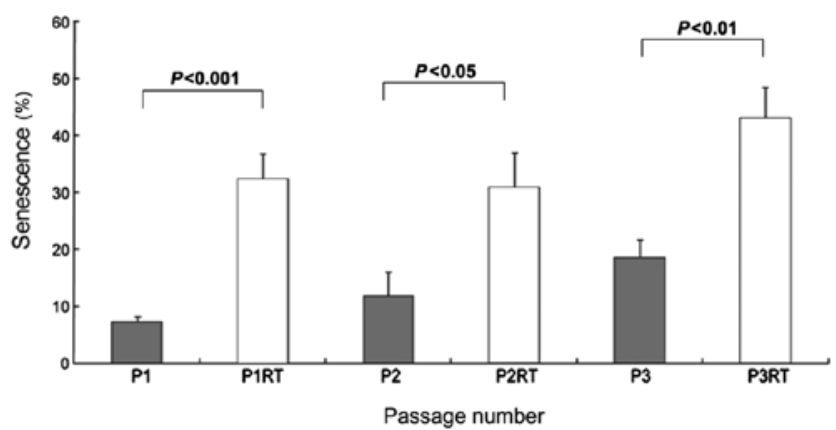

Figure 2. Effects of irradiation on human umbilical vein endothelial cell (HUVEC) senescence. Irradiation-induced senescence of HUVECs at all PNs. HUVECs were irradiated at room temperature at $2 \mathrm{~Gy} / \mathrm{min}$. Irradiated HUVECs were cultured for 8 days, and then cellular senescence was evaluated by senescence-associated (SA)- $\beta$-galactosidase assay. Data shown are the means \pm SD from 3 independent experiments. RT indicates that the cells were treated with irradiation. PN, passage number; P1, PN1; P2, PN2; P3, PN3.

induced a delay in senescence, and that hTERT-overexpressed ECs appeared more resistant to stress (26). Certain studies have demonstrated that telomerase inhibitors increase the sensitivity of cancer cells to IR. Nakamura et al showed that 


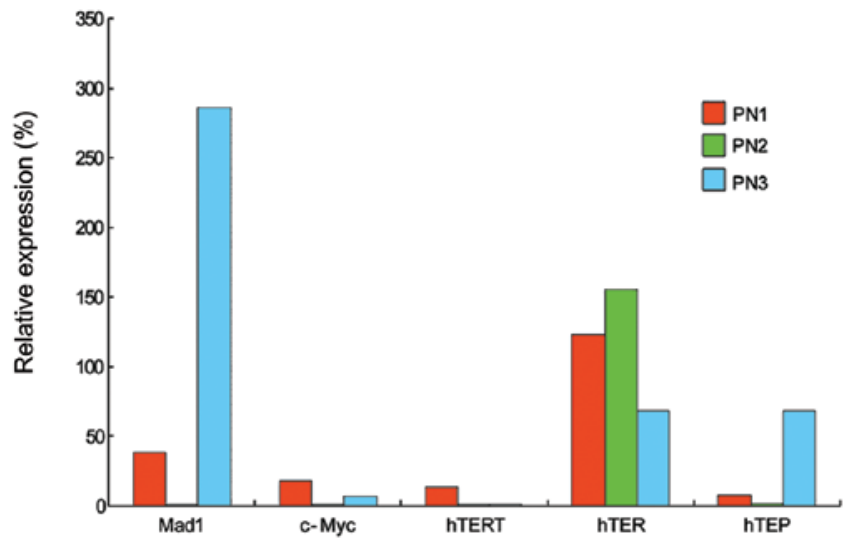

Figure 3. Changes in relative gene expression of Madl,c-Myc, hTERT, hTER and $h T E P$. Human umbilical vein endothelial cells (HUVECs) were irradiated at room temperature at $2 \mathrm{~Gy} / \mathrm{min}$. Irradiated HUVECs were cultured for 8 days and then harvested for the evaluation of gene expression. Real-time PCR was carried out once for each telomerase-related gene. Relative gene expression was the ratio of expression of irradiated HUVECs and that of the control HUVECs at the same PN. Zero (0) indicates that the gene was not expressed or the expression was below the range of detection. PN, passage number; $h T E R T$; human telomerase reverse transcriptase.

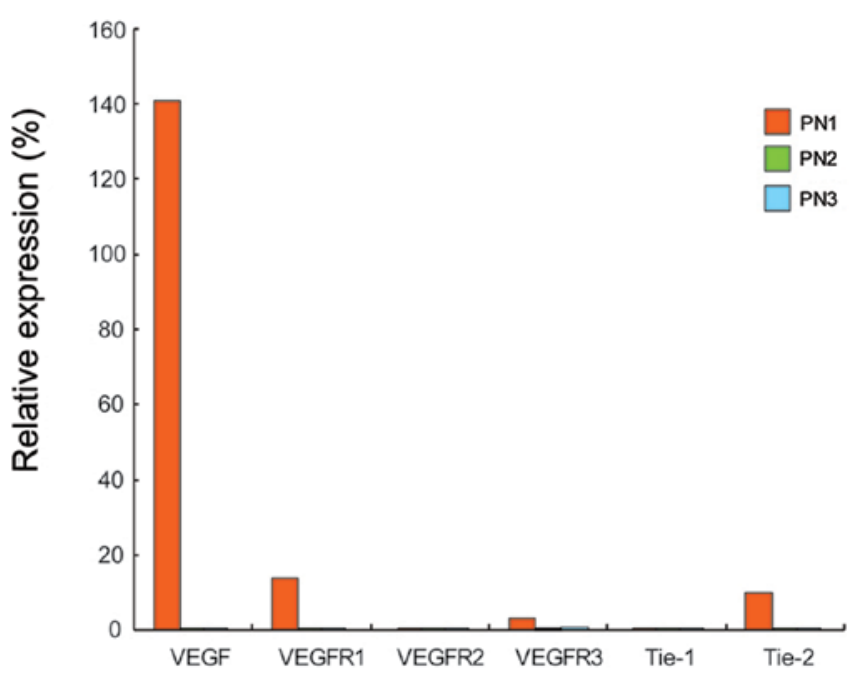

Figure 4. Changes in relative gene expression of $V E G F, V E G F R 1, V E G F R 2$, VEGFR3,Tie-1 and Tie-2. Human umbilical vein endothelial cells (HUVECs) were irradiated at room temperature at $2 \mathrm{~Gy} / \mathrm{min}$. Irradiated HUVECs were cultured for 8 days and then harvested for the evaluation of gene expression. Real-time PCR was carried out once for each angiogenesis-related gene. Relative gene expression was the ratio of expression of irradiated HUVECs and that of the control HUVECs at the same PN. Zero (0) indicates that the gene was not expressed or the expression was beneath the range of detection. PN, passage number. VEGF, vascular endothelial growth factor; VEGFR, vascular endothelial growth factor receptor.

HeLa cells lacking $h T E R T$ treated with small interfering RNAs had a decreased telomerase activity and a significantly increased sensitivity to radiation compared with control cells (6). Wu et al reported that treatment with imetelstat, a telomerase antagonist, reduced the telomerase activity of esophageal cells by more than $70 \%$ compared to the controls. In addition, imetelstat increased the number and size of 53BP1 foci following IR (27).

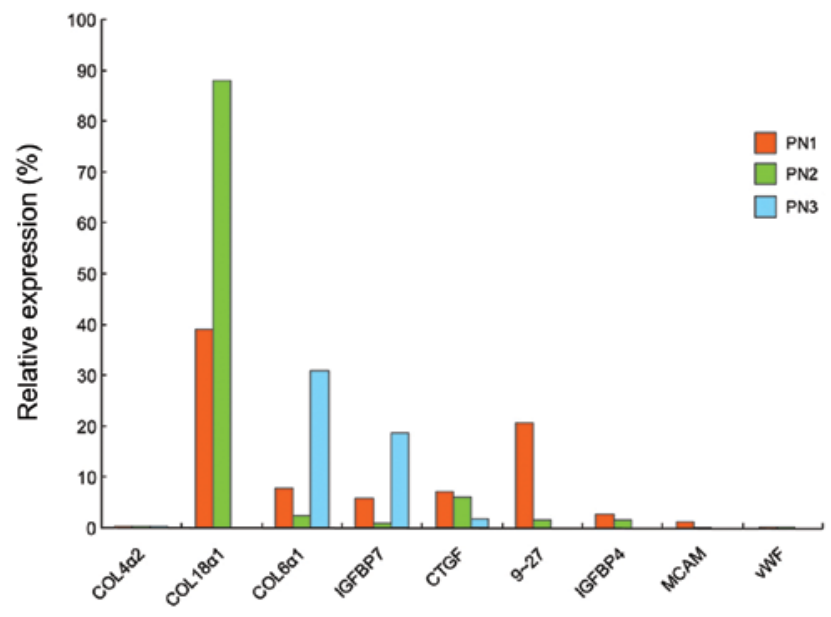

Figure 5. Changes in relative gene expression in COL4 $\alpha 2, C O L 18 \alpha 1, C O L 6 \alpha 1$, $I G F B P 7, C T G F, 9-27, I G F B P 4, M C A M$ and $v W F$. HUVECs were irradiated at room temperature at $2 \mathrm{~Gy} / \mathrm{min}$. Irradiated HUVECs were cultured for 8 days and then harvested for the evaluation of gene expression. Real-time PCR was carried out once for each angiogenesis-related gene. Relative gene expression was the ratio of expression of irradiated HUVECs and that of the control HUVECs at the same PNs. COL18 1 1, 9-27, IGFBP4, MCAM and $v W F$ gene expression in irradiated HUVECs were not evaluated at PN3. PN, passage number; $C O L 4 \alpha 2$, collagen type IV, $\alpha 2$; COL18 $\alpha 1$, collagen type XVIII, $\alpha$; COL6 $\alpha 1$, collagen type VI, $\alpha 1$; IGFBP, insulin-like growth factor-binding protein; $C T G F$, connective tissue growth factor; $M C A M$, melanoma cell adhesion molecule; $v W F$, von Willebrand factor.
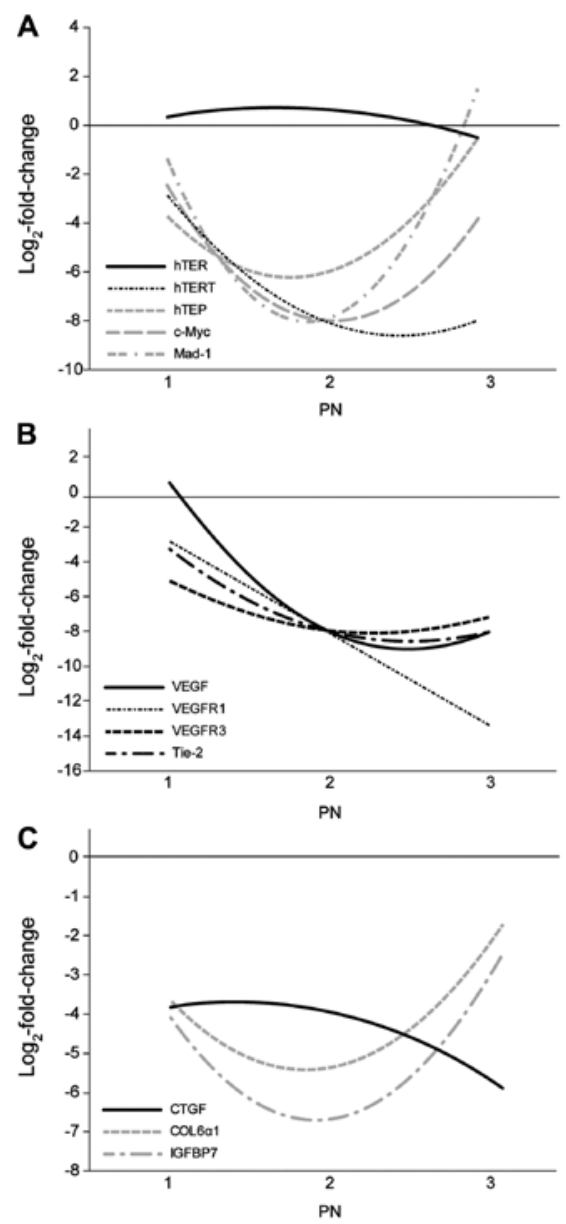

Figure 6. Expression fold change in telomerase- and angiogenesis-related genes was calculated as the $\log _{2}$ ratio of the fold change between irradiated human umbilical vein endothelial cells (HUVECs) and control HUVECs at the same PNs. Only the fold change of Mad-1 increased over zero. PN, passage number. 
In our study, the number of senescent cells increased in the irradiated HUVECs, while the telomerase activity and hTERT expression were decreased. $c$-Myc expression was also downregulated following IR. By contrast, the expression of Madl in the irradiated cells increased by approximately 3 -fold compared to the control cells at PN3. The regulation of hTERT expression is a major control mechanism of telomerase activity (3). The hTERT promoter contains several binding sites for transcription factors, including c-Myc and Mad1 (28). Mad1 is a transcriptional repressor that represses the c-Myc-mediated transactivation by competing for the ubiquitous binding partner, Max, preventing it from binding to c-Myc. The hTERT promoter contains 2 E-box consensus sites. One is located close to the translational initiation codon at position -29 to -34 (proximal E-box), and the other is located at position -238 to -243 with regard to the ATG (distal E-box). c-Myc and Mad1 exert their transcriptional effects by binding to the same site in the hTERT promoter (3). Though we have no direct evidence that IR directly regulates $c-M y c$ and MadI expression, these data suggest that the upregulation of Madl and the downregulation of $c-M y c$ in irradiated HUVECs deactivate $h T E R T$.

In the present study, $V E G F$, as well as $c-M y c$ were downregulated in the irradiated HUVECs during serial passage. c-Myc has been shown to increase VEGF production in several cell types (29). Myc-overexpressing B cells have been shown to increase VEGF production during the early stages of lymphomagenesis in $\mathrm{E} \mu-c-M y c$ mice (29). The $V E G F$ promoter contains a consensus Myc-binding site. In addition, VEGF induces $h T E R T$ expression and telomerase activity in human ECs (30). We suggested that the downregulation of $c-M y c$ in irradiated HUVECs was associated with the downregulation of $V E G F$, which contributed to the IR-induced hTERT downregulation. However, there is little evidence that c-Myc directly induces VEGF mRNA transcription (29). Further studies are required to evaluate the correlation among c-Myc, hTERT and VEGF expression in irradiated HUVECs.

The expression of endothelial markers, such as VEGFR2, vWF and MCAM, is known to increase during endothelial progenitor cell differentiation toward ECs (31). Considering that IR decreased the expression of these markers in our study, IR may negatively modulate the differentiation of endothelial progenitor cells toward ECs. IR may hinder the ability of endothelial progenitor cells to adhere, migrate and form a capillary-like structure (31). This may be one of the mechanisms of action of IR in tumor angiogenesis.

In conclusion, IR can induce human microvascular EC senescence at doses relevant to clinical radiotherapy. During the serial passage of irradiated HUVECs, the expression of hTERT, $c-M y c$ and VEGF was downregulated. The data presented in this study may aid in the understanding of the mechanisms behind IR-induced EC senescence and telomerase- and angiogenesis-related gene response.

\section{Acknowledgements}

This study was supported by a grant from the Korea Health 21 R\&D Project, Ministry of Health and Welfare, Republic of Korea (0405-BC01-0604-0002). We are grateful to Mr. Dong-Su Jang for the illustrations.

\section{References}

1. Garcia-Barros M, Paris F, Cordon-Cardo C, Lyden D, Rafii S, Haimovitz-Friedman A, Fuks Z and Kolesnick R: Tumor response to radiotherapy regulated by endothelial cell apoptosis. Science 300: 1155-1159, 2003.

2. Li J, Huang S, Armstrong EA, Fowler JF and Harari PM: Angiogenesis and radiation response modulation after vascular endothelial growth factor receptor-2 (VEGFR2) blockade. Int J Radiat Oncol Biol Phys 62: 1477-1485, 2005.

3. Gunes C, Lichtsteiner S, Vasserot AP and Englert C: Expression of the hTERT gene is regulated at the level of transcriptional initiation and repressed by Mad1. Cancer Res 60: 2116-2121, 2000.

4. Calado RT and Young NS: Telomere diseases. N Engl J Med 361: 2353-2365, 2009.

5. Grimes A and Chandra SB: Significance of cellular senescence in aging and cancer. Cancer Res Treat 41: 187-195, 2009.

6. Nakamura M, Masutomi K, Kyo S, Hashimoto M, Maida Y, Kanaya T, Tanaka M, Hahn WC and Inoue M: Efficient inhibition of human telomerase reverse transcriptase expression by RNA interference sensitizes cancer cells to ionizing radiation and chemotherapy. Hum Gene Ther 16: 859-868, 2005.

7. Pallini R, Pierconti F, Falchetti ML, D'Arcangelo D, Fernandez E, Maira G, D'A mbrosio E and Larocca LM: Evidence for telomerase involvement in the angiogenesis of astrocytic tumors: expression of human telomerase reverse transcriptase messenger RNA by vascular endothelial cells. J Neurosurg 94: 961-971, 2001.

8. Falchetti ML, Mongiardi MP, Fiorenzo P, Petrucci G, Pierconti F, D'Agnano I, D'Alessandris G, Alessandri G, Gelati M, Ricci-Vitiani L, Maira G, Larocca LM, Levi A and Pallini R: Inhibition of telomerase in the endothelial cells disrupts tumor angiogenesis in glioblastoma xenografts. Int J Cancer 122: 1236-1242, 2008.

9. Bu DX, Johansson ME, Ren J, Xu DW, Johnson FB, Edfeldt K and Yan ZQ: Nuclear factor \{kappa\}B-mediated transactivation of telomerase prevents intimal smooth muscle cell from replicative senescence during vascular repair. Arterioscler Thromb Vasc Biol 30: 2604-2610, 2010.

10. Dvorak HF: Vascular permeability factor/vascular endothelial growth factor: a critical cytokine in tumor angiogenesis and a potential target for diagnosis and therapy. J Clin Oncol 20: 4368-4380, 2002.

11. Damianovich D and Tebbutt NC: Role of novel targeted agents in the treatment of metastatic colorectal cancer. Asia Pac J Clin Oncol 3: 2-11, 2007.

12. Watanabe Y, Lee SW, Detmar M, Ajioka I and Dvorak HF: Vascular permeability factor/vascular endothelial growth factor (VPF/VEGF) delays and induces escape from senescence in human dermal microvascular endothelial cells. Oncogene 14: 2025-2032, 1997.

13. Seegar TC, Eller B, Tzvetkova-Robev D, Kolev MV, Henderson SC, Nikolov DB and Barton WA: Tie1-Tie2 interactions mediate functional differences between angiopoietin ligands. Mol Cell 37: 643-655, 2010.

14. Kurz DJ, Hong Y, Trivier E, Huang HL, Decary S, Zang GH, Luscher TF and Erusalimsky JD: Fibroblast growth factor-2, but not vascular endothelial growth factor, upregulates telomerase activity in human endothelial cells. Arterioscler Thromb Vasc Biol 23: 748-754, 2003.

15. Oliner J, Min H, Leal J, Yu D, Rao S, You E, Tang X, Kim H, Meyer S, Han SJ, Hawkins N, Rosenfeld R, Davy E, Graham K, Jacobsen F, Stevenson S, Ho J, Chen Q, Hartmann T, Michaels M, Kelley M, Li L, Sitney K, Martin F, Sun JR, Zhang N, Lu J, Estrada J, Kumar R, Coxon A, Kaufman S, Pretorius J, Scully S, Cattley R, Payton M, Coats S, Nguyen L, Desilva B, Ndifor A, Hayward I, Radinsky R, Boone T and Kendall R: Suppression of angiogenesis and tumor growth by selective inhibition of angiopoietin-2. Cancer Cell 6: 507-516, 2004.

16. St Croix B, Rago C, Velculescu V, Traverso G, Romans KE, Montgomery E, Lal A, Riggins GJ, Lengauer C, Vogelstein B and Kinzler KW: Genes expressed in human tumor endothelium. Science 289: 1197-1202, 2000.

17. Kalluri R: Basement membranes: structure, assembly and role in tumour angiogenesis. Nat Rev Cancer 3: 422-433, 2003.

18. Durai R, Yang SY, Sales KM, Seifalian AM, Goldspink G and Winslet MC: Insulin-like growth factor binding protein-4 gene therapy increases apoptosis by altering $\mathrm{Bcl}-2$ and Bax proteins and decreases angiogenesis in colorectal cancer. Int J Oncol 30: 883-888, 2007. 
19. Roth JM, Akalu A, Zelmanovich A, Policarpio D, Ng B, MacDonald S, Formenti S, Liebes L and Brooks PC: Recombinant alpha2(IV)NC1 domain inhibits tumor cell-extracellular matrix interactions, induces cellular senescence, and inhibits tumor growth in vivo. Am J Pathol 166: 901-911, 2005.

20. Itasaka S, Komaki R, Herbst RS, Shibuya K, Shintani T, Hunter NR, Onn A, Bucana CD, Milas L, Ang KK and O'Reilly MS: Endostatin improves radioresponse and blocks tumor revascularization after radiation therapy for A431 xenografts in mice. Int J Radiat Oncol Biol Phys 67: 870-878, 2007.

21. Ria R, Todoerti K, Berardi S, Coluccia AM, De Luisi A, Mattioli M, Ronchetti D, Morabito F, Guarini A, Petrucci MT, Dammacco F, Ribatti D, Neri A and Vacca A: Gene expression profiling of bone marrow endothelial cells in patients with multiple myeloma. Clin Cancer Res 15: 5369-5378, 2009.

22. Hong EH, Lee SJ, Kim JS, Lee KH, Um HD, Kim JH, Kim SJ, Kim JI and Hwang SG: Ionizing radiation induces cellular senescence of articular chondrocytes via negative regulation of SIRT1 by p38 kinase. J Biol Chem 285: 1283-1295, 2010.

23. Igarashi K, Sakimoto I, Kataoka K, Ohta K and Miura M: Radiation-induced senescence-like phenotype in proliferating and plateau-phase vascular endothelial cells. Exp Cell Res 313: 3326-3336, 2007.

24. d'Adda di Fagagna F, Reaper PM, Clay-Farrace L, Fiegler H, Carr P, Von Zglinicki T, Saretzki G, Carter NP and Jackson SP A DNA damage checkpoint response in telomere-initiated senescence. Nature 426: 194-198, 2003.
25. Kim NW, Piatyszek MA, Prowse KR, Harley CB, West MD, Ho PL, Coviello GM, Wright WE, Weinrich SL and Shay JW: Specific association of human telomerase activity with immortal cells and cancer. Science 266: 2011-2015, 1994.

26. Takano H, Murasawa S and Asahara T: Functional and gene expression analysis of hTERT overexpressed endothelial cells. Biologics 2: 547-554, 2008 .

27. Wu X, Smavadati S, Nordfjall K, Karlsson K, Qvarnstrom F, Simonsson M, Bergqvist M, Gryaznov S, Ekman S and Paulsson-Karlsson Y: Telomerase antagonist imetelstat inhibits esophageal cancer cell growth and increases radiation-induced DNA breaks. Biochim Biophys Acta 1823: 2130-2135, 2012.

28. Lin SY and Elledge SJ: Multiple tumor suppressor pathways negatively regulate telomerase. Cell 113: 881-889, 2003.

29. Mezquita P, Parghi SS, Brandvold KA and Ruddell A: Myc regulates VEGF production in $\mathrm{B}$ cells by stimulating initiation of VEGF mRNA translation. Oncogene 24: 889-901, 2005.

30. Zaccagnini G, Gaetano C, Della Pietra L, Nanni S, Grasselli A, Mangoni A, Benvenuto R, Fabrizi M, Truffa S, Germani A, Moretti F, Pontecorvi A, Sacchi A, Bacchetti S, Capogrossi MC and Farsetti A: Telomerase mediates vascular endothelial growth factor-dependent responsiveness in a rat model of hind limb ischemia. J Biol Chem 280: 14790-14798, 2005.

31. Tian F, Liang PH and Li LY: Inhibition of endothelial progenitor cell differentiation by VEGI. Blood 113: 5352-5360, 2009. 